\title{
Making engaging online videos: What can higher education teachers learn from YouTubers?
}

\author{
Neil Cowie and Keiko Sakui
}

\begin{abstract}
Videos are an indispensable part of most online courses and are a key device for teachers to develop a personal link with their learners. There are a number of technical principles which can guide teachers to make videos that will best enhance learning and engagement. However, not many teachers have expertise in creating videos and it is not always clear how students perceive the educational value of such videos. In this preliminary study, the authors, who are both English as a Foreign Language teachers at university in Japan, shared clips from popular YouTube language teachers with student participants in order to find out what features of the videos were most appealing. Results show a number of principles to follow especially concerning voice speed, clarity and friendliness. But above all teachers need to show an authenticity and passion about their subject.
\end{abstract}

Keywords: online videos, student engagement, language learning.

\section{Introduction}

There are many kinds of online courses where a significant proportion of the course consists of different kinds of linear videos that are designed to be watched asynchronously. Such videos include lecture recordings, screencasts, slides with audio, animation, and 'talking head' videos where the presenter/teacher talks directly to the camera in order to communicate with learners.

There are a number of features of video production that can help students more easily process information and hence retain their interest. Mayer (2009) has been at the forefront of research into how to better present multimedia materials and has identified a number of well-known principles including those of 'coherence' (remove extraneous information), 'signalling' (highlight what you want to teach through contrast) and 'temporal contiguity' (present information through different channels of information, such as audio and visual, at the same time). Mayer has also put forward the principle that if a learner 'feels social partnership' (2017, p. 414) with an instructor they will try harder and have better learning outcomes. Mayer makes the suggestion that instructors personalise their talk by using 'I', 'we' and 'you'. This clearly connects to the well-known 'Community of Inquiry' framework for e-learning (Garrison, Anderson \& Archer, 1999; Garrison, 2011) based on three overlapping aspects of 'presence' (social, cognitive and teaching). The most pertinent of these for this paper is that of teaching and social presence which interact to set the climate of a learning community (Nolan-Grant, 2019). In terms of creating videos, what this highlights is how teachers can project themselves in the best way to engage with learners. In a large-scale study of student engagement on MOOCs, Guo, Jim and Rubin (2014) concluded that engagement could be increased by making shorter videos with personalised talking heads and presenters should speak enthusiastically. This is an approach echoed by Fyfield, Henderson, Heinrich and Redmond (2019) who call for more research into the 'affective dimensions of video design in motivating student interest' (p. 2).

Educational videos are posted in formats ranging from a series of lessons that make up a course to individual ones. MOOCs and university lectures are one example of courses sitting at the formal institutional end of a spectrum with open non-formal courses at the other (Rha, 2018). The latter are hosted by commercial platforms where course creators develop and market myriad courses to students all over the world. Examples include Udemy, Skillshare, Teachable, BJYU's and Tencent Classroom. 
These informal learning platforms are extremely popular; for example, Udemy (https://www.udemy.com) states that as of January 2020 it has over 50 million students and 57,000 instructors. In addition to videos uploaded to formal and informal online courses there are also an increasing number of educational videos uploaded to video-sharing sites such as YouTube (Lebedev \& Sharma, 2019). These may be linked with a specific curriculum such as the Khan Academy (Gray, Lindstrøm \& Vestli, 2017) or an individual YouTuber's creation of standalone videos. The number of views that such videos receive can be in the millions. Of course, ten million views does not imply ten million individual students but it is still an impressive rate. Most recently, due to COVID-19 and the mass move to online teaching (Crawford, Butler-Henderson, Rudolph \& Glowatz, 2020), teachers from all kinds of backgrounds have been pushed to create videos to share online with students that they would normally meet face-to-face in the classroom or lecture theatre (Li \& Lalani, 2020; Lowenthal, Borup, West, \& Archambault, 2020).

In the field of language teaching, formal institutional learning through schools and universities and informal learning on commercial platforms have existed in parallel. This means that instructors at formal institutions have not generally paid much attention to the kinds of informal learning students are taking advantage of in their free time. However, it is important to explore what insights can be gained from the techniques and methods that video creators for informal online learning have been adopting. This distinction between formal and informal learning is not as clearly defined as it used to be and digital technology is increasingly making these boundaries blurry as Anderson (2007) describes in 'The Long Tail'. The long tail is a marketing phenomenon whereby consumers can buy niche products located at the end of the long tail. For example, the expertise and knowledge to create a video used to be only available to a small number of professionals but with the advancement of technology these are now available to laypeople. The production of TV programmes was only possible in a well-equipped studio with highly trained professionals; whereas now high-quality video clips can be created in someone's bedroom with a smartphone and editing software. The result has been an explosion of online video content, including ones for educational purposes.

The authors are two English as a Foreign Language (EFL) teachers at university in Japan with several years of experience of creating videos for informal open online courses in language learning. As a result of researching technology use in language teaching (Cowie \& Sakui, 2019) we have also become increasingly aware of the power and influence of informal learning platforms in language teaching. Instead of ignoring them, however, we have decided to investigate students' perspectives on educational videos available in informal learning settings. In this paper, therefore, we will focus on lessons learned from a preliminary study in which language learning students were surveyed and interviewed about various features of talking head YouTube videos. This study was carried out to answer the following research question:

\section{How do students respond to informal educational videos and what features of such videos do students find engaging?}

It is our aim that the identification of the features of an engaging video will be particularly useful to university teachers who suddenly find themselves teaching online and have few opportunities to directly teach their students. Although our study is limited to the field of language teaching, it is our intention that the findings will inform instructors in other fields who wish to make their videos more engaging. In doing so we hope that this maximize educational opportunities and improve learning outcomes for students.

\section{The study}

Six language learning video clips from popular YouTube teachers were selected to compare different teaching styles. In order to minimise variation between the clips, three men and three women who were 
all so-called 'native speakers' (Phillipson, 2012) from Australia, the UK, and the US were chosen. All had a history of uploading videos to YouTube and a large number of subscribers and views (for example, Clip 1 had had over six million views). A further limit on variation between the videos was they were all focused on pronunciation, especially individual sounds.

Language students at two universities in Japan were recruited for the study in a form of convenience sampling (Jager, Putnick \& Bornstein, 2017). At the time of writing the authors have received 69 replies to the survey and conducted seven follow-up interviews. The data collection is ongoing.

\section{Participants}

Table 1: Participant data $(\mathrm{N}=69)$

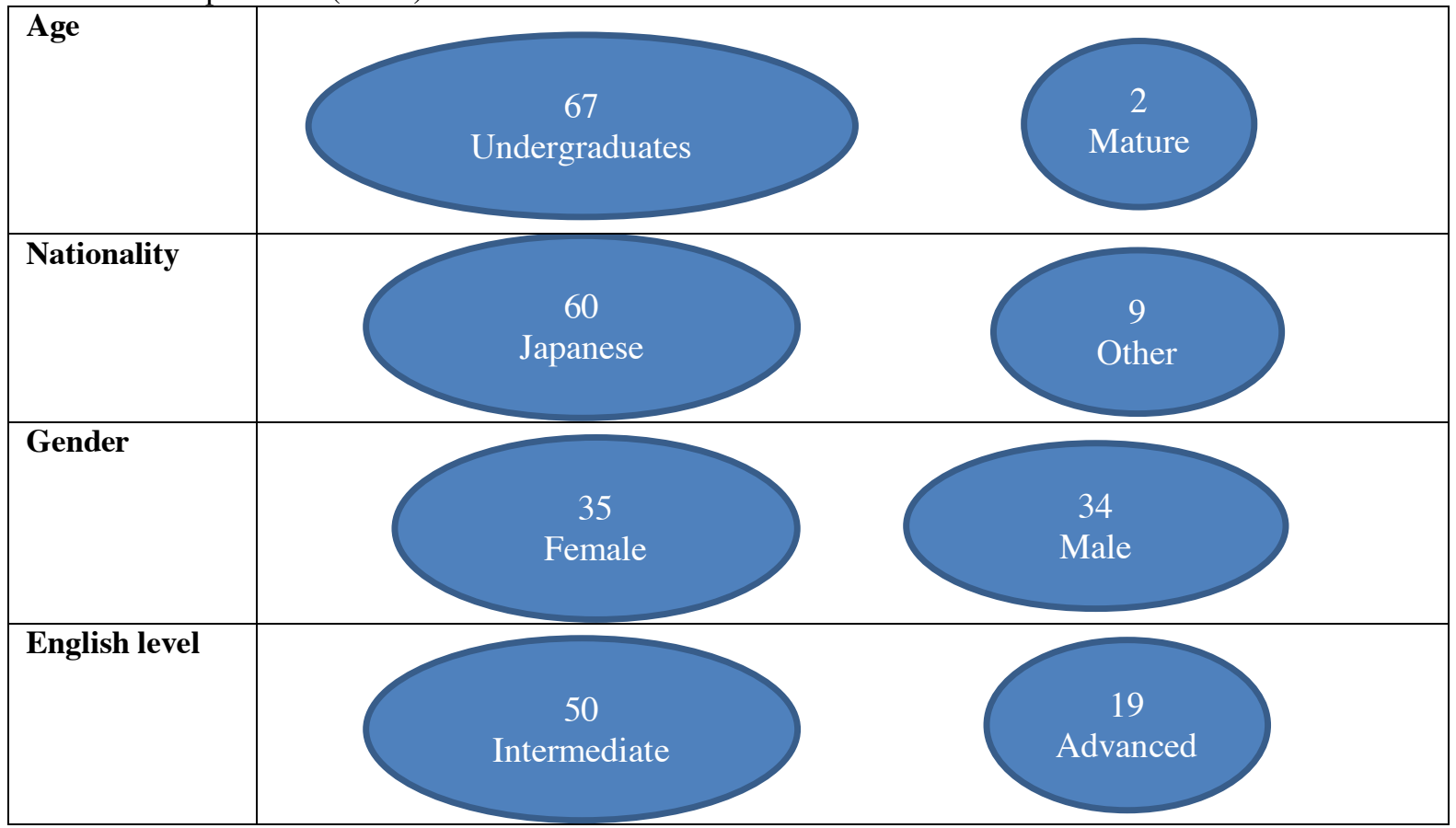

Table 1 shows that most participants were in the 19-21-year undergraduate age bracket, most were Japanese, there was a fairly even gender split, and based on the classes that they came from it was estimated that they were from intermediate to advanced level (TOEIC levels 600 to 900).

\section{Survey and interview questions}

Each participant watched the first two minutes of all of the six video clips and then completed an online survey. The authors were trying to elicit from the participants a kind of instinctive reaction to the videos as to which were more engaging and which were they most likely to keep watching. At the end of the online survey was an invitation to a follow-up interview. The online survey included questions on a five-point Likert scale concerning the following features of each video: the size of the presenter's talking head; the presenter's emotional tone; the relevance or otherwise of the background behind the presenter; the presenter's voice speed and clarity; whether the presenter was easy to understand or not; whether the on-screen text (not subtitles) was helpful or not; whether the presenter was interesting; and, the likelihood of whether the participants would want to continue to view the video or not. The final question was the main original research topic of this study, but all the other questions were based on previous features that emerged from the research literature.

In the follow-up interviews, participants were asked to elaborate on the answers that they had given to 
the survey (What was it about her voice that you didn't like? Could you explain what you mean by 'too feminine'?);

and were also asked various supplementary questions such as: What kind of online videos do you like? What are the good and bad points of online learning?

\section{Data analysis}

The answers to the surveys were analysed in terms of simple percentages and ranking of various features. The interviews were transcribed and coded in to various themes (Miles, Huberman \& Saldana, 2014).

\section{Survey results}

The survey identified a clear ranking amongst the six YouTube teachers as to which were the most and least popular amongst the participants. The two most important reasons for the popular videos were that they were clear and at an appropriate speed. Other important factors were that they were not boring, straight to the point, humorous and attractive. Conversely, the main reasons why videos were not popular were basically the opposite for why videos were liked. The two most common reasons were that the presenter was too slow and boring. Interestingly, the lowest ranked presenter was seen as scary and rude.

At this stage, it would seem we could recommend a number of simple principles for the creators of language learning videos: speak at an appropriate speed, be clear about what you want to say, and be friendly. However, the results are not that straightforward. What we are most interested in is which videos are most engaging to students and, thus, why some videos may have higher educational value than others. Certainly, participants could rank the video teachers into the most popular and that they would like to continue to watch them, but even the lowest ranked teacher had a considerable number of participants who wanted to continue to watch her. Let us turn to the interview data for some insights into why participants would want to continue watching the less popular presenters.

\section{Interview results}

There are five features that a teacher/video creator can manipulate to maximise engagement. The two most important factors are that the teacher shows an authenticity and a passion about what they are teaching. Here are some quotations to illustrate this (names are pseudonyms):

'She has a unique personality, expresses her own opinions and was sarcastic and interesting.' (Ai) 'I like passionate, interesting presenters who are "performing."' (Takeshi)

'She has a big personality.' (Helen)

Two further features are that learners want their online courses to be clearly structured and that the teacher is pushing them in some way:

'If there is no test or exam there is less push to keep watching.' (Rachel)

'There is nobody to push you.' (Nobohiro)

Finally, one feature that echoes one of Mayer's (2009) principles is the use of text to support the talking head. The YouTube teachers presented textual information in two main ways: on a whiteboard that was present throughout the video and as a brief pop up at the moment the speaker mentioned specific information. The participants stressed that both kinds of text display are useful to keep following what is being said as long as there was not too much information that they were distracted by it. This particularly seemed to be the case with one teacher's whiteboard that had too much information. An 
added benefit for some participants of a whiteboard was that it made them feel that they were in a classroom and that it was a real learning situation.

\section{Discussion}

This preliminary study is small in scale and the findings are tentative but it demonstrates that there are quite a range of individual differences and there is no clear 'template' that we can recommend to video creators. We hope that this is actually a reassuring result for teachers who are creating their own videos. In other words, this result ensures some freedom to each individual teacher that they do not have to fit in a particular mould but can decide what contents to select, what order to present them in, and how to deliver them. Some participants may find one presenter interesting and others find them irritating. However, there are some overarching approaches that we recommend teachers take if they want to increase the chances of their videos being seen as engaging.

Firstly, try to speak at an appropriate speed for your audience, be as clear as possible, and be friendly rather than rude or scary. Secondly, try to be genuine and communicate a level of passion. This is not easy to communicate in a video and this is why some YouTubers are more successful than others. We would encourage university teachers to try to talk to the camera in a way that shows you care, that you are not talking in a monotone, and that you have a genuine delight in your subject. Thirdly, even though they want to study in an autonomous manner learners said that they need to be pushed. This can be achieved by structuring materials in a progressive manner and by showing a genuine interest in helping learners to learn the content. There are of course many ways that online courses can be clearly structured but perhaps these are not always signalled directly in a video - so giving explicit links to previous lessons and subsequent ones can help give a feeling of structure and continuity.

There are a number of limitations to this survey. Primarily there need to be more participants to make any findings more robust and trustworthy. For future research, it would be helpful to contrast videos made within different cultural traditions (these were all English 'native speakers' so it would insightful to widen the presenter profile) and to include more formal teaching settings such as in university lectures. Similarly, these were language learning videos and student participants so it would be extremely useful to include other subject specific comparisons

\section{Conclusion}

There are an increasing number of videos being used in many forms of online learning. In order to maximise learning and student retention it is important to make these videos as engaging as possible. Past research on multimedia learning focused on a number of technical principles that can be used to achieve such engagement. The study in this paper, using clips from successful YouTube language teachers, has identified a number of additional ways to enhance engagement. The most important, but probably hardest to achieve, is for teachers to imbue their videos with a sense of genuine authenticity and passion.

\section{References}

Anderson, C. (2007). The Long Tail: How Endless Choice Is Creating Unlimited Demand. London: Random House.

Cowie, N., \& Sakui, K. (2019). Enhancing student retention rates on open non-formal online language learning courses. Pacific Journal of Technology Enhanced Learning, 1(1), 15-24. ttps://doi.org/10.24135/pjtel.v1i1.17

Crawford, J., Butler-Henderson, K., Rudolph, J., \& Glowatz, M. (2020). COVID-19: Twenty countries' higher education intra-period digital pedagogy responses. Journal of Applied Teaching and Learning, 3(1). https://doi.org/10.37074/jalt.2020.3.1.7 
Fyfield, M., Henderson, M., Heinrich, E., \& Redmond, P. (2019). Videos in higher education: Making the most of a good thing. Australasian Journal of Educational Technology, 35(5), 1-7. https://doi.org/10.14742/ajet.5930

Garrison, D. R., Anderson, T., \& Archer, W. (1999). Critical inquiry in a text-based environment: Computer conferencing in higher education. The Internet and Higher Education, 2(2-3), 87-105. https://doi.org/10.1016/s1096-7516(00)00016-6

Garrison, D. R. (2011). E-learning in the 21st century: A framework for research and practice. (2nd ed.). New York, NY: Routledge. http://dx.doi.org/10.4324/9780203166093

Gray, J., Lindstrøm, C., \& Vestli, K. (2017). Khan Academy as a resource for pre-service teachers: A controlled study. CERME 10, Feb 2017, Dublin, Ireland. https://hal.archives-ouvertes.fr/hal-01946341

Guo, P. J., Kim, J., \& Rubin, R. (2014). How video production affects student engagement: An empirical study of MOOC videos. In Proceedings of the first ACM conference on Learning at Scale Conference (pp. 41-50). https://doi.org/10.1145/2556325.2566239

Lebedev, P., \& Sharma, M. D. (2019). Riddles on YouTube: Investigating the potential to engage viewers in reflective thinking. Research in Learning Technology, 27. https://doi.org/10.25304/rlt.v27.2280

Li, C., \& Lalani, F. (2020). The COVID-19 pandemic has changed education forever. This is how. World Economic Forum. https:/www.weforum.org/agenda/2020/04/coronavirus-education-global-covid19online-digital-learning/

Lowenthal, P., Borup, J., West, R., \& Archambault, L. (2020). Thinking beyond Zoom: Using asynchronous video to maintain connection and engagement during the covid-19 pandemic. Journal of Technology and Teacher Education, 28(2), 383-391. https://www.learntechlib.org/primary/p/216192

Jager, J., Putnick, D. L., \& Bornstein, M. H. (2017). More than just convenient: The scientific merits of homogeneous convenience samples. Monographs of the Society for Research in Child Development, 82(2), 13-30. https://doi.org/10.1111/mono.12296

Mayer, R. E. (2009). Multimedia Learning (2nd ed.). New York, NY: Cambridge University Press.

Mayer, R. E. (2017). Using multimedia for e-learning. Journal of Computer Assisted Learning, 33, 403-423. https//doi.org/10.1111/jcal/12197

Miles, M.B., Huberman, A.M., \& Saldana, J. (2014). Qualitative Data Analysis: A Methods Sourcebook. London: Sage.

Nolan-Grant, C. R. (2019). The Community of Inquiry framework as learning design model: A case study in postgraduate online education. Research in Learning Technology, 27. https://doi.org/10.25304/rlt.v27.2240

Phillipson, R. (2018). Linguistic Imperialism. In C.A. Chapelle (Ed.), The Encyclopedia of Applied Linguistics (pp. 1-7) doi:10.1002/9781405198431.wbeal0718.pub2

Rha, H.M. (2018). A study on the classification of online education types and development of quality management indicators for lifelong vocational skills development. In T. Bastiaens et al. (Eds.). Proceedings of EdMedia: World Conference on Educational Media and Technology (pp. 759- 763). Amsterdam, Netherlands: Association for the Advancement of Computing in Education (AACE). https://www.learntechlib.org/p/184274

Cowie, N. \& Sakui, K. (2020). Making engaging online videos: What can higher education teachers learn from YouTubers? In S. Gregory, S. Warburton, \& M. Parkes (Eds.), ASCILITE's First Virtual Conference. Proceedings ASCILITE 2020 in Armidale (pp. 71-76). https://doi.org/10.14742/ascilite2020.0105

Note: All published papers are refereed, having undergone a double-blind peer-review process.

The author(s) assign a Creative Commons by attribution licence enabling others to distribute, remix, tweak, and build upon their work, even commercially, as long as credit is given to the author(s) for the original creation.

() Cowie, N. \& Sakui, K. 2020 